\title{
Innovation in Tradition: Key Success Factors of New Entrepreneurs in the Retail Trade
}

\author{
Beatrice Luceri ${ }^{1}$, Edoardo Sabbadin ${ }^{1}$, Cristina Zerbini ${ }^{1}$ \\ ${ }^{1}$ Department of Economics and Management, University of Parma, Parma, Italy \\ Correspondence: Cristina Zerbini, Department of Economics and Management, University of Parma, Parma, \\ Italy.
}

Received: August 1, 2017

doi:10.5539/ibr.v10n12p239
Accepted: September 26, $2017 \quad$ Online Published: November 23, 2017

URL: https://doi.org/10.5539/ibr.v10n12p239

\begin{abstract}
Have the economic crisis, the digital revolution and the growth of mass retailing changed the success factors of small retailing companies? What impact have they had on the characteristics of the profiles of new entrepreneurs in the retail trade? On the basis of the data collected through a qualitative research by a semi-structured interview on a sample of retailers, the paper aims to provide answers to these questions.

The results of the interviews, recorded, transcribed and analysed using the software T-Lab 8.1, highlight the new success factors and, in particular, the key role assumed by web marketing. Moreover, the fact that the retail sector has maintained a strong capacity to create employment is cause for reflection on the employment potential of the small companies in the more traditional sectors. The importance of this sector appears even more significant if we consider the context of economic instability and declining consumption in which these companies are operating.
\end{abstract}

Keywords: retail trade, retailer micro enterprise, new entrepreneurs, qualitative research

\section{Introduction}

For a long time now economic literature has considered the retail trade as a residual sector, not very competitive and innovative, and protected from international competition. All negative features, tolerated only due to the positive contribution that the sector has always guaranteed to the country in terms of employment. The two great poles of the retail trade, food and non-food, have shared the same fate, but at different times. In Italy, mass retailing made its entry into the food sector in the Sixties and experienced rapid development which appears today to have come to the end of its cycle. Self service points of sale with ever increasing dimensions, grouped in corporate and/or contractual forms, have facilitated the concentration of this sector. In Italy, 28,232 modern points of sale account for $59 \%$ of the market (according to AC Nielsen estimates, 2013). The modernisation of the non-food sector of the retail trade finally arrived - thirty years late. As of the Nineties, the points of sale started to get bigger and large specialised retailing outlets began to attract the demand, to the detriment of traditional retailers. Although high, the competitive pressure exerted by the modern component over the traditional one has generated lower levels of concentration in the non-food supply compared to the food supply. Non-food modern retailing concentrates $44 \%$ on sales, despite the fact that it has 2,064 more shops (thereby topping a total of 30,000 units), so the economic importance of Italian non-food Mass Retailing is 15 percentage points less than the analogous channel in the food sector (according to AC Nielsen estimates, 2013). So the data point to a framework featuring a distribution network in which specialised, small retailers demonstrate a tenacity that is unequalled in Europe. Although it lost sales units in the period 2011-2013 (from 526,791 to 513,201 stores; according to Federdistribuzione estimates), the traditional stores still play an important economic role in Italy, mediating $41 \%$ of the sales of non-food products (against $42 \%$ in 2011). Signals of revitalisation are observable also in the food sector where the number of points of sale has increased by 1,965 businesses in 2013 compared to the previous year, amounting to a total of 513,201 sales units. Thus, notwithstanding the undisputed leadership of modern retailing, in the food trade traditional retailing maintains a sizeable market share of approx 18\% (according to AC Nielsen estimates, 2013).

In Italian literature several studies focused on the retail trade following a sectorial logic, on the contrary, a limited number focused on small retail businesses from an economic/managerial perspective. The main reason is the fragmentation of the supply which impedes a structured activity of managerial research, only accessible from 
a certain dimension, due to the economic investment and human resources it requires. Otherwise, modern retailing which aroused the interest of researchers thanks to the availability of much more detailed data on the consumer (scanner data and loyalty cards) (e.g. Castaldo, 2013; Lugli G., 2009; Pellegrini \& Zanderighi, 2013; Sciarelli \& Vona, 2008; Burt, 2010; Burt, Sparks, \& Teller, 2010). Traditional retailing appears deserving (worthy) of the same attention as modern retailing because, not only is it far from being on the decline, but it also manifests great energy and capacity for innovation (Beaver \& Jennings, 2005; Man, Lau \& Snape, 2008; Mitchelmore \& Rowley, 2010; Soto-Acosta, Popa, \& Palacios-Marqués, 2016; Mazzei, Flynn, \& Haynie, 2016). Recently, small retailers have been prompted to change by the growing preference manifested by consumers to the electronic retailing channel which (Da Costa, 2016; Sin et al., 2016), paradoxically, has also increased the demand for traditional services. Other driving factors are the aging of the population and a different way of experiencing city life in which the role of the car has been dramatically reduced. The challenge that neighbourhood points of sale will have to face in the near future is to continue to offer value in a context dominated by increasingly more custom-tailored forms of selling.

The aim of this study is to investigate the success factors of retailing microenterprises and analyse the employment potential of the Italian microenterprise sector, in which organisational, economic, social and emotional dynamics are mixed. Particular attention is dedicated to traditional non-food retailing given its economic importance. The analysis focuses on Lombardy, the most competitive region in Italy which has followed a development model based on mass retailing in its various point of sale formats: Shopping Malls, Factory Outlets, Hypermarkets, Superstores and Large Specialist Retailing Outlets. Also the presence of branch offices and franchising systems is higher here than in other Italian regions. So the choice fell on a context in which competitive pressure is so high that the solutions found by traditional retailers tend to represent anticipative, innovative and effective strategic paths for the sector as a whole and valid also for other areas of the country.

\section{Method}

The investigation was conducted in 2014 through a semi-structured interview addressed to a sample of 8 entrepreneurs who had set up retail businesses in the last two years. Young (30-40 years) or adults (40-60 years), the new entrepreneurs were characterised by a fairly good level of education. Before entering the retail sector, almost all of them had had previous work experience.

The interviews were carried out on the basis of pre-set questions, posed in the same way and in the same order to all of the interviewees. At the same time, they were also allowed to express themselves spontaneously. The interviewer also had the same freedom and could pose additional questions depending on the specific relational dynamics of each interview.

The conversations were recorded and subsequently transcribed so that their contents could be analysed. The activity was conducted in two phases. In the first phase, two researchers read the transcripts separately in order to familiarise themselves with the data and classify the text on the basis of pre-set themes (theory driven approach). In the second phase, the researchers reread the transcripts together, discussed any classification differences and reached an appropriate agreement on their interpretation.

In support of the analysis of the contents, the software T-Lab 8.1 was used; this made it possible to analyse the text more or less automatically, using statistical and lexical techniques.

Overall, a total of 21,353 words were identified and the processing of the texts produced the following results:

- the relevant key words and the relations between them;

- the association between the key words.

What connotes the words as being representative of the contents of the text is the frequency with which they appear (at least four times), while relevance increases with the frequency. It should be specified that some lexical forms were grouped under a single headword.

An overview of the relation between key words is provided by the multidimensional scaling map: the length of the words is a proxy for their importance, while their closeness is a proxy for the intensity of the relationship between them. The axes were labelled on the basis of the words present in the boxes and the theme to which they refer.

\section{Results}

The conceptual map that small entrepreneurs construct with reference to the success factors of a retailing company at a fixed place of business appears comprehensive and not at all simplistic (Fig. 1). The headwords quoted and the way in which they are placed in relation to one another take into account the complexity inherent 
in doing business, but - even more important - acknowledge the fact that entrepreneurs are well aware of this. The words most frequently used are point of sale, services, social network, internet, marketing, franchisor, skills and competition. Each of these hides a complex structure of marketing levers to be used to navigate with relative ease in the fast-flowing waters of the market.

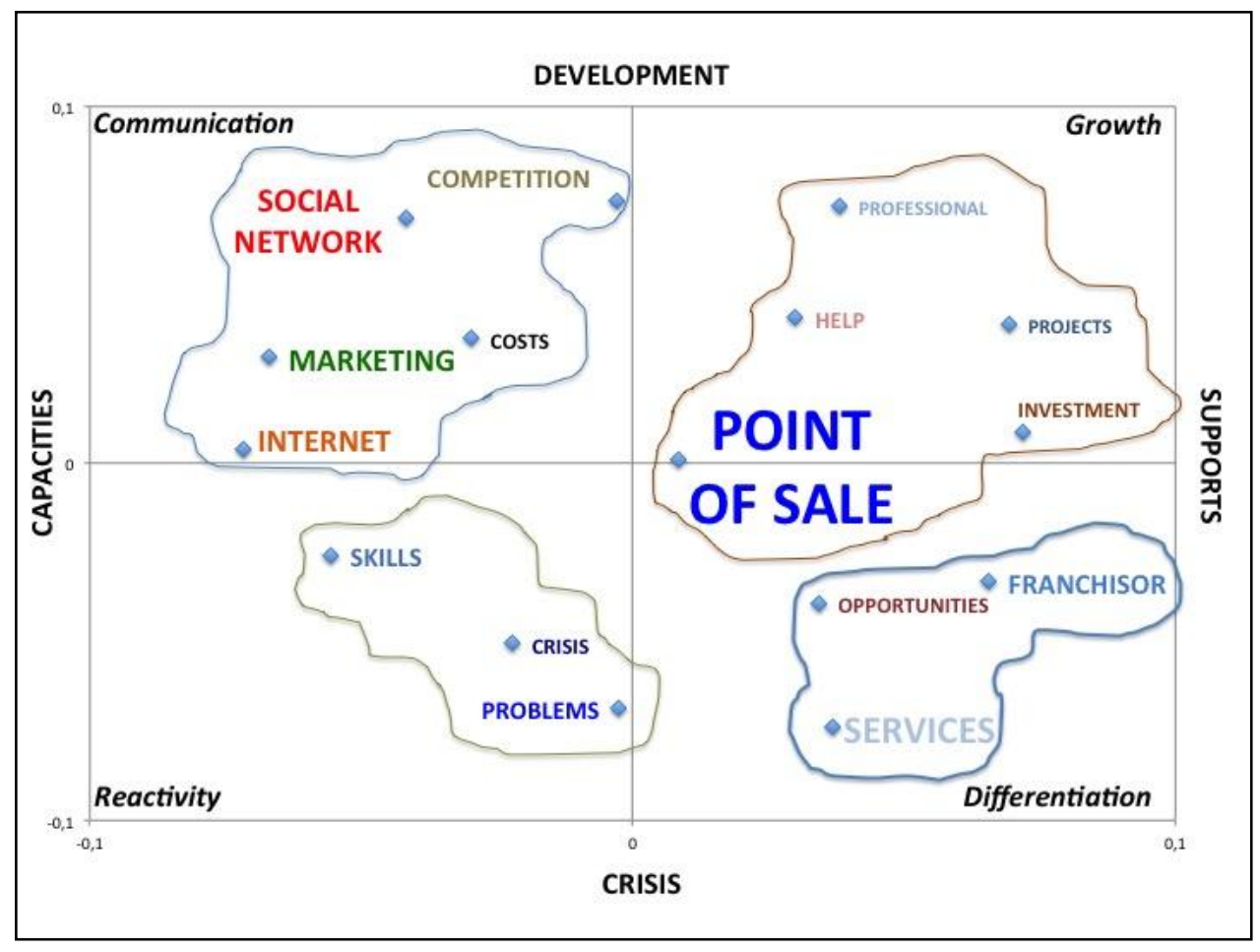

Figure 1. Success factors: conceptual map (multidimensional scaling map)

Four thematic areas can be identified, organised around two axes: development/crisis and capacities/supports. The first places the entrepreneur in the current situation (crisis) and projects him/her into the future (development); the second identifies the know-how required for success on the market (capacities) and tools needed to achieve these (supports). The four thematic areas that identify the success factors of small entrepreneurs are: communication, growth, reactivity and differentiation.

"Growth" box

Growth depends solely on the capacity to offer a product, or a point of sale, with the power to fully satisfy the customer's requirements. An attractive setting ranks among the first factors of success because it is the place in which the customer's purchasing experience takes place. As such, all the elements composing it (architecture, decor, furnishing accessories etc.) produce a halo effect on the assessment of the quality of the service received and, therefore, on the degree of satisfaction obtained.

The cost of store design solutions can be resolved in two ways: creativity in the search for innovative solutions at a sustainable cost and the use of the friendship network in order to obtain professional advice cheaply (or, even better, free of charge) in order to meld the various elements of the store space into a well-integrated whole that is attractive to the eye of the customer. This requires a thorough change of perspective. The point of departure shifts: from the standard format of a point of sale for a product sector which involves the finding of the necessary financial resources, to a unique point of sale format that can be achieved with resources in line with the budget available. In other words, the economic security of the activity is assured, since the design idea must be sustainable and in line with the pre-set maximum expenditure limit. Among the various alternatives for the point of sale format, the winning solution will be the one that complies with this limit, provided that it is aligned with the market positioning of the service offered.

Many people think that this design project was studied in depth with who knows what kind of investment, in order to manage to create this pseudo-salvaged vintage effect. For me this is an incredible compliment. Because we really did salvage the materials, because we had no money, but people think that there is some really sophisticated, high-budget work behind the design. And saying that it looks like a really 
expensive design, ultra-researched to recreate a vintage look is the best compliment they could pay me, because it really is all that we could afford.

We consulted our architect and interior decor friends, and were helped by an interior designer friend. All on a very human level. [...] Then we had other friends, who are still taking care of the packaging and graphics. [...] And they, together with our interior designer friend created a match between the furniture and all the rest.

"Differentiation" box

The experience recounted by the entrepreneurs seems to indicate the development of new point of sale formats, using to advantage the increase in the demand for services. A product innovation leading to the success of a distribution network that could be defined as service-dominant retailing, i.e. specialised retailing distinguished by a product mix with a predominantly high service content. In order to differentiate itself from modern retailing, neighbourhood retailing redefines the product-service mix in favour of the latter. So the more traditional activity of retailing becomes secondary and ancillary to the provision of new services which become the core business of the retailing companies. An example of this trend is a case study which was the subject of an interview: a small network of points of sale under franchising (three in Milan and one in Lodi) called PCBuster (www.pcbuster.it). The company started operating with a focus on IT assistance services for the general public and small companies. Only after the initial launching phase and at the request of the clientele itself did it progressively extend its activities to the retailing of accessories for PCs. However, this second component of its product mix provided a marginal contribution to its overall turnover and was functional to being able to offer a complete service.

Service is, unquestionably, becoming a highly requested factor once more. For example, an elderly person comes in with an old mobile phone and is afraid of having to replace it: "What will happen if I put the SIM card in another device? Will I lose everything? I don 't understand the new mobile phones". And Fabrizio, my business partner, who comes from a similar experience to mine is very patient. He takes the customers' problems in hand and resolves them, obtaining very positive results. Our business grows by word of mouth. Yesterday evening a lady came in and said: "Is it true that if I bring my mother here with her new mobile phone that you will move the memories for her and explain to her how it works?"

We have a shop that sells sweets and wedding favours, and we are just starting to enter the party planner and entertainment sector for children. I have a girl who works alongside me in this when I call her, because obviously we develop the various projects on the basis of the demand and the customer's budget.

The second imperative to guarantee success is to offer value to the customer with a product that is unique and which stands out in comparison to the competition. The opportunities for traditional retailing exist, albeit in a niche market, because the watchword of mass retailing and franchising chains is "standardisation". This is the condition required for developing the brand and obtaining economies of scale (both internally and in negotiations with suppliers). There is nothing negative about all this, except for the fact that this marketing policy creates a supply gap which can be filled by offering the consumer something different. In a nutshell, the retailer can get a share of the market if she/he does not forget the elementary rules of business: understanding whether unsatisfied needs exist, developing a distinctive product to offer customers and letting them know about it.

Hairdressers' and bars keeping opening up. There's no point in creating so many businesses doing the same thing. Since there is already so much competition with shopping malls attached, the possibility probably exists to create, first and foremost, original business activities, because I read an article which recommended that before opening a shop and choosing what kind of shop to open, you should create a niche market and work on an aspect that is different from all the other businesses that can be found anywhere and everywhere. [...] You have to be different from the competition. This is a success factor.

[...] because shopping malls have all become clones of one another now. Even the development of franchising systems and networks of shops have led to standardisation, most probably due to the policies imposed by the franchisors. But in the end the consumer arrives at the following conclusion: I might as well go there, it's the same as the other place.

"Communication" box

Communication occupies a prominent position among the factors that determine the success of a business. An activity which all entrepreneurs consider no longer separable from the internet and the social networks, which must be added to the more traditional methods of communication. The store sign, visual merchandising, product packaging, the shopping bag and business cards are all important elements of communication, as is the capacity to communicate in the places that the consumer visits. And more and more of these places are becoming virtual. 
"The times are past when it was sufficient to have a nice shop window to attract customers and prompt them to enter the shop"; now "we have to go and get the customers where they are, and that's the internet" (Barbara Barazzoni, entrepreneur).

Some entrepreneurs have become proficient in the use of the most popular and widely used social network, i.e. Facebook. A page dedicated to the store makes it possible to communicate what it can offer and tempt the customer to come to the point of sale to purchase the product that may have caught his/her attention. Providing the selling price is an important factor for attracting customers. It is the store's way of telling the customer: "I sell products with different prices; among these you will be sure to find something that you like and can afford" (Barbara Barazzoni, entrepreneur). In addition to handling relations with regular customers, social networks offer the possibility of a much more powerful word of mouth in terms of the number of contacts that can be reached in comparison to purely physical contact. Relying on the internet for evaluating the alternatives and reading the comments of those who have had a direct experience reduces the risk of uncertainty and promotes sales. Last but not least, online communication is a valid alternative to traditional communication, such as for example, flyering. In the case of microenterprises, the profit and loss account is often unable to bear such costs.

However, the other side of the coin reveals that: firstly, it is crucial to be proficient in information technology and communication; secondly, this activity is time-consuming. Neither one nor the other condition can be taken for granted: the entrepreneur needs to be extremely adaptable to change. The alternative is to address the market, suffering the consequences of lack of integration and tardiness in the updating of information. There is nothing more deleterious for a company than to set up a virtual showcase and then fail to consistently update its contents. If visitors/customers find nothing new they will soon stop visiting the company's websites because they do not see the point in doing so.

To sum up, leveraging on communication is important, as is putting it into practice on the internet. The logical consequence of this is that retail companies with a fixed place of business have a substantial need for training and technical support.

Graphics, marketing, are vitally important, yes, for starting up a business or otherwise, because nowadays a lot of people use mobile phones, Facebook. It is a basic thing in the sense that everybody looks at Facebook at least 10 times a day, so if you create and promote your activity on this social network, in the right way [...]

I have chosen a freelance, companies, agencies that will create a website for me next week, because since I have kids who are 22 years old, they offered to help, but I realised that someone is needed to keep it up to date, someone who will work on it, maybe not every day, but a lot, and they can't do it, since they are at University.

"Reactivity" box

The capacity of entrepreneurs to react to the current situation of crisis and, more in general, to the problems they have to deal with, is closely linked to the competences they possess. It is a commonly shared opinion that previous experience plays a fundamental role in the success of a new retailing business. Moreover, in the case of new enterprises with several partners, the interviewees stressed the importance of the complementarity of the various competences acquired by these partners. In the majority of cases, it happens by chance, but it would be a good idea actually to plan it. In brief, experience is a potential source of competitive advantage because it enables the entrepreneur to orient him/herself in the world of business. Competences imply operating know-how with regard to the supply offered to the market.

Yes, complementarity of competences may be considered a success factor: we always say that we are $33.3 \%$ competences. Of course, I deal with communication and brand management. We were lucky because the complementarity of our competences was natural: we were all completely different and we had all reached a turning point, which had to be that of creating something of value for ourselves.

I decided to open a business in line with my experience because I was absolutely sure that this would put me at an advantage.

At the same time, also continuous training is an important factor with a view to consolidating/developing the business because it ensures that the competences possessed will continue to improve and develop. Opportunities for improvement are important because the entrepreneur tends to underestimate this aspect, and thinks that success has already been achieved when the business is set up. Compared to the past, the internet offers a wide range of opportunities for learning at relatively reasonable costs. Here we refer not only to e-learning, but also to the collective intelligence which specialist networks contribute to developing. 
For me training is fundamental. Let me tell you, absurd as it may be, we are a sweet shop which also makes wedding favours. At the end of April, I took a course on all that revolves around wedding favours because even although I have the manual dexterity required plus 10 years' experience in retailing, it is still always advisable to keep up to date. So I always try to take some courses each year for this reason. Paradoxically, even although it is a small town shop, the fact of having studied English privately is a plus point for me, when foreign tourists come to town.

\section{Conclusions}

Unemployment in Italy, which has dropped below 13\%, remains one of the country's main problems because it triggers vicious circles which are increasingly more difficult to break. In the face of this situation, which sectors and which enterprises can contribute most to reducing this phenomenon?

Already in the course of the first serious post-war economic crisis (that of the Seventies), the idea of reviewing the economic role of the small company began to make inroads. Economists realised that in the years in which the oil crisis ignited inflation, the large Italian industrial groups were busy restructuring their businesses, reducing personnel and increasing unemployment. In contrast, the small companies - particularly those with 6 to 9 employees - were managing to create new jobs. The same thing happened in the services sector, which catalysed the interest of researchers for this very reason. Today, following the crisis that began in 2008, it is legitimate to ask whether the profile of the new entrepreneurs in the retailing sector has changed.

None of the new entrepreneurs analysed in this paper was a young unemployed person without work experience. Everyone interviewed had previous work experience, confirming that business stems from business. In other words, the majority of the start-ups were actually spin-offs.

Two distinct segments of the new entrepreneurs can be identified.

The first is composed of young people aged between 30 and 40 years of age, with previous work experience, who start up a business out of choice and not because they have been forced out of the labour market. These new young entrepreneurs prefer to do business by teaming up with ex-colleagues (not alone), and they are highly motivated on a personal level: they want to demonstrate that they are capable of developing a business idea, even in such difficult times for the country as the present.

The second segment groups older entrepreneurs (40-55 years). Almost all of these people have been unemployed for a year or two because they were forced to resign and they are seeking new sources of income. The majority $(70-80 \%)$ of the new entrepreneurs interviewed from this segment were university graduates and/or former executives.

Another interesting result of the survey was that investment in a new enterprise can exert a significant leverage effect on employment. For example, the entrepreneur interviewed, who started off with a partner, declared that he had invested 100,000 euro in a business which, in 2014, generated three permanent jobs. In another case, three partners in their thirties who, in May 2012, invested a total of 200,000 euro in a mixed craft and retailing business, generated fifteen permanent jobs in 2015, including those of the three partners.

Another significant result obtained from the interviews conducted was that, without the support of a trade association, it is almost impossible for a new entrepreneur - even a graduate with over twenty years' experience as an employee - to fulfil all the legal obligations laid down for founding and starting up a new enterprise, even in a sector with low entry barriers such as that of retailing.

Also emerging from the survey was the progressive development of new hybrid distribution formats which require a new, well-balanced mix of services from catering to retailing. This could be the result of the knock-on effect deriving from the development of new types of point of sale by organised mass retailing companies, such as the entrepreneur Oscar Farinetti's Eataly, which are widely publicised by the mass media.

Some of the interviews and cases analysed also highlight that in order to have success the new retailing microenterprises have to conduct marketing activities such as creating a brand/store sign, designing an display space that will create a warm, attractive atmosphere (to convey a positive, emotional marketing experience) and exploit the potential of web marketing. These are all activities that an independent entrepreneur - even a young, capable one with specific competences - cannot develop autonomously. In order to achieve this goal, a network of professionals with different specialist competences is needed. In other words, even retailing microenterprises with a fixed place of business must be able to access advanced marketing services in order to find a share of the market in a sector that is becoming more and more competitive, with sluggish or declining demand. In that regard, we encountered cases of new independent retailing entrepreneurs who organised themselves with the aid of an informal network of relations with professionals specialised in the activities described above and, first and 
foremost, the graphics, the furnishing of the point of sale and web marketing.

Last but not least, the maintaining, by the retailing company, of a strong ability to create jobs: it is, in fact, the sector with the largest number of employees in the world.

Italian literature has mainly concentrated on the modernisation of distribution, the economic effects deriving from the industrialisation of the supply of retailing services - through the adoption of the self service format and the vertical relationships of the distribution channel. It is important to remember that there is not just an economic, managerial and marketing dimension, but also a social, urban and tourist dimension, which must be considered. The separate management of these two dimensions produces "non-places" (Augè, 2008), i.e. artificial groupings specialised in the exchange of products that contribute to creating dormitory districts and suburbs, characterised by urban discomfort. When intelligently integrated, the retail trade becomes a driver for territorial development with the power to regenerate entire districts. Points of sale are, in fact, places in which goods, information, experiences and emotions are exchanged.

\section{Acknowledgements}

The authors would like to thank Eupolis Lombardia for the research grant and the Unità Organizzativa Commercio, Reti Distributive e Tutela dei Consumatori (Unit for the organisation of trade, distribution networks and consumer protection) of the Lombardy Region, especially Dr. Paolo Mora, for his support during the data collection phase.

\section{References}

Augé, M. (2008). Nonluoghi. Introduzione a una antropologia della surmodernità. Milano, Elèuthera.

Beaver, G., \& Jennings, P. (2005). Competitive advantage and entrepreneurial power: The dark side of entrepreneurship. Journal of Small Business and Enterprise Development, 12(1), 9-23. https://doi.org/10.1108/14626000510579617

Burt, S. (2010). Retailing in Europe: 20 years on. The International Review of Retail, Distribution and Consumer Research, 20(1), 9-27. https://doi.org/10.1080/09593960903497773

Burt, S., Sparks, L., \& Teller, C. (2010). Retailing in the United Kingdom-a synopsis. European Retail Research, 24(1), 173-194. https://doi.org/10.1007/978-3-8349-8938-3_8

Castaldo, S. (2013). Channel and Retail Management. Cheltenhamm, Edward Elgar.

Da Costa, E. (2016). Global e-commerce strategies for small businesses. Mit Press.

Lugli, G. (2009). Marketing Distributivo, la creazione di valore nella distribuzione specializzata. Torino, UTET.

Man, T. W., Lau, T., \& Snape, E. (2008). Entrepreneurial competencies and the performance of small and medium enterprises: an investigation through a framework of competitiveness. Journal of Small Business \& Entrepreneurship, 21(3), 257-276. https://doi.org/10.1080/08276331.2008.10593424

Mazzei, M. J., Flynn, C. B., \& Haynie, J. J. (2016). Moving beyond initial success: Promoting innovation in small businesses through high-performance work practices. Business Horizons, 59(1), 51-60. https://doi.org/10.1016/j.bushor.2015.08.004

Mitchelmore, S., \& Rowley, J. (2010). Entrepreneurial competencies: a literature reviewand development agenda. International Journal of Entrepreneurial Behaviour \& Research, 16(2), 92-111. https://doi.org/10.1108/13552551011026995

Pellegrini, L., \& Zanderighi, L. (2013). Il sistema distributivo italiano. Dalla regolamentazione al mercato. Bologna, Il Mulino.

Sciarelli, S., \& Vona, R. (2008). Management della distribuzione. Milano, McGraw-Hill.

Sin, K. Y., Osman, A., Salahuddin, S. N., Abdullah, S., Lim, Y. J., \& Sim, C. L. (2016). Relative Advantage and Competitive Pressure towards Implementation of E-commerce: Overview of Small and Medium Enterprises (SMEs). Procedia Economics and Finance, 35, 434-443. https://doi.org/10.1016/S2212-5671(16)00054-X

Soto-Acosta, P., Popa, S., \& Palacios-Marqués, D. (2016). E-business, organizational innovation and firm performance in manufacturing SMEs: an empirical study in Spain. Technological and Economic Development of Economy, 22(6), 885-904. https://doi.org/10.3846/20294913.2015.1074126

\section{Copyrights}

Copyright for this article is retained by the author(s), with first publication rights granted to the journal.

This is an open-access article distributed under the terms and conditions of the Creative Commons Attribution license (http://creativecommons.org/licenses/by/4.0/). 